\section{Dr. Werner R. Janoschek}

\author{
IUGS Treasurer
}

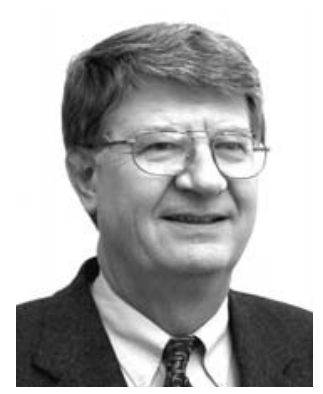

Werner R. Janoschek was born on the 6th February, 1940, in Vienna. He attended the University of Vienna from 1958 to 1963, where he studied geology, palaeontology and petrology. His thesis was on the Austro-Alpine Flysch Zone and the Helvetic Zone in the northern part of the Austrian Lake District (Salzkammergut).

He joined the Geological Survey of Austria in 1963 as a field geologist working in the Northern Calcareous Alps. He was also involved in the field of applied geosciences, and later joined the Petroleum Department of the Geological Survey. In 1971, he became deputy head, and in 1976 subsequently head of that department. During the first 'Oil crisis' he started to investigate the possibility of alternative energies in Austria, and promoted the application of geothermal energy for heating. He was a member of the OECD working group on renewable energy - geothermal energy for several years.

The Petroleum Department of the Geological Survey of Austria traditionally managed the international relations of the Geological Survey. Therefore, Werner Janoschek became familiar first of all with the connections to the neighbouring countries to the east, but soon enhanced the Survey's overall international contacts. Even today, the international relations of the Survey are one of the most challenging duties for him. In this connection, he became President of the Carpathian-Balkan Geological Association, and he is the International Coordinator of Section A Geology of the Earth Science Committee of the Central European Initiative (CEI, a political body consisting of 16 countries of the region, comprising e.g. Italy and Austria in the west, Ukraine and Moldavia in the east, and Bosnia and Herzegovina as well as Albania in the southeast.)

Especially after the dramatic change in the political and economic system in Central and Eastern Europe after 1990 the relationship between geological surveys in both parts of Europe had to be renewed, and he tried successfully to enhance the bilateral and multilateral contacts. Frequent visits to many of these countries allowed Werner Janoschek to become well acquianted with the situation of the geological surveys and institutes in these countries.

Werner Janoschek has been Austria's Chief Delegate or Deputy Chief Delegate to all the International Geological Congresses and the IUGS General Assemblies since 1976. He is a member of many scientific societies in Austria and abroad, and has been a member for many years of the board of the Austrian Geological Society (he has been President since 1999), of the Austrian Society of Petroleum Sciences (he was President for two terms) and of the Geologische Vereinigung. In addition, he was elected an Honorary Member of the Geological Societies of Hungary, Poland and the Slovak Republic. $\mathrm{He}$ is a member of the Austrian National Committee of Geology, and was one of the leading persons involved in the reorganization (1989-1991) of the National Committee of Geology, of which he is presently Vice President. He is also a member of the Austrian National Committee for the IGCP, and participates regularly in the Meetings of the Scientific Board as an observer. Since 1980, Werner Janoschek has been the Austrian representative to the Commission of the Geological Map of the World (CGMW). He is also a member of the Advisory Board for Environmental Protection of the Community of Vienna.

Werner Janoschek's career at the Survey continued in January 1979 (after a complete reorganization of the Survey), when he became Head of the Division of Geology. Since that time he has been a member of the Board of the Survey, and is responsible for the geological mapping program of Austria and for the basic research at the Survey. In addition, he became Vice Director in October 1983, and continued to be actively involved in the international relations of the Survey. In March 1994, he took over the leadership of the Division of Information Services and was involved in the increasing tasks of modern data retrieval and information technology. Since the end of the 1980s, he has promoted the computerization of the Geological Survey and the application of Geographic Information Systems for the completion of geological maps.

The inclusion of Austria within the European Union brought new challenges to the Geological Survey. An association of the geological surveys of the member countries (+ Norway, Iceland and Switzerland) was founded (EuroGeoSurveys) and Werner Janoschek became the main contact person between the Geological Survey of Austria and the EuroGeoSurveys.

A new challenge for Werner Janoschek started in August 2000, when he was elected Treasurer of the IUGS, based on his long experience in international cooperation and on his management skills. On April 1st 2001, he decided to retire from the Geological Survey, but he is still fully supported by the Survey and the Federal Ministry of Education, Research and Culture to exercise the function of Treasurer of the IUGS. Therefore, his telephone and fax numbers, and email address remain unchanged.

As he has been working for many years mainly in the field of Earth Science Management, he has had little time for his own scientific work. However, some 30 papers and many lectures are proof of his active involvement in the geosciences.

His hobbies include classical and jazz music, theatre and literature, cultural events and foreign travel. Since June 1968, he has been married to Margit and has two children: Bettina, born in 1974, and Peter, born in 1977. He and his wife live in a villa in a residential district in the westernmost part of Vienna next to the "Lainzer Tiergarten" (former imperial hunting resort).

\section{Address:}

Dr. Werner Janoschek

IUGS Treasurer

Austrian Geological Survey

Rasumofskygasse 23

Postfach 127

A-1031 Vienna

AUSTRIA

Tel: +431 1125674, ext. 400

Fax: +431712567456

E-mail:wjanoschek@cc.geolba.ac.at 